\title{
El sexo y la ciudad. Homosociabilidad y disidencia en Berlin Alexanderplatz de Alfred Döblin
}

\author{
[Sex and the City. Homosociability and Sexual Dissidence in Berlin Alexanderplatz by \\ Alfred Döblin] \\ http://dx.doi.org/10.11606/1982-88372444374
}

Atilio Raúl Rubino ${ }^{1}$

\begin{abstract}
The novel Berlin Alexanderplatz (1929) by Alfred Döblin appears in a time and space of enormous political excitement and also of sex-dissident militancy, the Berlin of the Weimar Republic. Composed as a montage of the voices of the big city, the novel allows us to enter into many of the tensions, discussions and militancies of the time around sexual dissidence. This article, therefore, takes a look at these sex-dissident representations in Berlin Alexanderplatz to think about them in tension with the production and reproduction of heterosexual masculinity. In contrast to this sexual effervescence of 1920s Berlin, I am also interested in thinking about the production of the cisheteromasculinities thought of from the concept of homosexuality, fundamentally in the relationship between the characters of Franz and Reinhold. In this way, this point can also be linked to the violence and aggression against women, which are very marked in Döblin's novel, and, mainly, to the exchange of women between Franz and Reinhold.
\end{abstract}

Keywords: Alfred Döblin; Berlin Alexanderplatz; Homosociability; Sexual dissent.

Resumen: La novela de Berlin Alexanderplatz (1929) de Alfred Döblin surge en una época y un espacio de enorme ebullición política y también de militancia sexo-disidente, el Berlín de la República de Weimar. Compuesta como un montaje de las voces de la gran ciudad, la novela deja ingresar muchas de las tensiones, discusiones y militancias de la época en torno a la disidencia sexual. Este artículo, en consecuencia, realiza un recorrido por esas representaciones sexodisidentes en Berlin Alexanderplatz para pensarlas en tensión con la producción y reproducción de la masculinidad heterosexual. En contraste con esta efervescencia sexual del Berlín de los años veinte, me interesa también pensar la producción de las cisheteromasculinidades pensada a partir del concepto de homosociabildiad, fundamentalmente en de la relación entre los personajes de Franz y Reinhold. De esta forma, se puede vincular también este punto con la violencia y agresividad contra la mujer, muy marcada en la novela de Döblin, y, principalmente, con el intercambio de mujeres entre Franz y Reinhold.

Palabras clave: Alfred Döblin; Berlin Alexanderplatz; Homosociabilidad; Disidencia sexual.

\footnotetext{
${ }^{1}$ CONICET, Universidad Nacional de La Plata (UNLP), Instituto de Investigaciones en Humanidades y Ciencias Sociales (UNLP/CONICET), Facultad de Humanidades y Ciencias de la Educación (FaHCEUNLP), Calle 51 e/ 124 y 125, Ensenada, Buenos Aires, Argentina. Email: atiliorubino@yahoo.com.ar. ORCID: 0000-0002-4576-5483
} 


\section{Una lectura sexo-disidente de la ciudad}

En una famosa nota de 1980, "Die Städte des Menschen und seine Seele" (recopilada luego en La anarquía de la imaginación, 2002), antes del estreno de su versión televisiva/cinematográfica de Berlin Alexanderplatz en 1980, Fassbinder da cuenta de la importancia que esta novela tiene no sólo para su obra teatral y cinematográfica, sino para su vida (FASSBINDER 2002: 195). Pero también, como hace en varias entrevistas, señala su propia lectura de la novela de Döblin. Para él se trata de una relación entre dos hombres que se hacen daño sólo porque no pueden reconocer que se aman (FASSBINDER, 2002: 196 у 2018: 415).

La versión audiovisual de Fassbinder propició una lectura queer de la novela de Döblin, centrándose en aspectos que, de todos modos, eran evidentes en Berlin Alexanderplatz. Me refiero, fundamentalmente, a la relación entre Franz Biberkopf, su protagonista, y Reinhold, el antagonista, que puede ser pensada como homoerótica. Pero también, a la presencia de sexualidades disidentes en toda la novela. En este sentido, es importante tener en cuenta que el Berlín de la República de Weimar fue el centro de una enorme ebullición sexo-disidente, de manifestaciones culturales y de militancia en contra de la persecución, particularmente del parágrafo 175 del código penal que prohibía las relaciones sexuales entre hombres, que rigió desde 1871, pero se recrudeció durante el nazismo, a partir del agregado de la sección $175^{\mathrm{a}}$. En los años anteriores al ascenso de Hitler al poder, había una fuerte militancia por su derogación. De hecho la película Anders als die andern (1919) es un claro ejemplo de ello. Dirigida por Richard Oswald y realizada gracias al Institut für Sexualwissenschaft de Berlín, creado y dirigido por Magnus Hirschfeld, uno de los primeros científicos y militantes por la causa de las minorías sexuales, Anders als die andern constituye la primera representación positiva de la homosexualidad en el cine. Se trata de una película militante que denuncia que la prohibición de relaciones sexuales entre varones sólo permite el accionar de chantajistas y sobornadores, de modo de mantener la homosexualidad en el más estricto secreto. En el período de entreguerras y durante la República de Weimar, además, existió también una fuerte militancia por la despenalización del parágrafo 218, que condenaba el aborto, así como una enorme cultura lesbiana. En esa época se produjo una importante apertura en cuanto a la disidencia sexual y su presencia social de la que obras literarias como Der fromme Tanz (1925) de Klaus Mann y Verwirrung der Gefühle (1925) de Stefan Zweig 
RUBINO, A.R. - Homosociabilidad y disidencia en Berlin Alexanderplatz

dan cuenta. También la cultura lésbica aparece de forma temprana en el marco de la literatura y el cine de la época, con, por ejemplo, la novela Gestern und Heute (Christa Winsloe, 1930) y su posterior adaptación cinematográfica Mädchen in Uniform (dir. Leontine Sagan, 1931), considerada una de las primeras películas de temática abiertamente lésbica.

Es necesario, entonces, revisar la presencia de sexualidades y disidencias sexogenéricas, así como el tratamiento de la masculinidad y de las relaciones heterosexuales y homosociales en Berlin Alexanderplatz. Die Geschichte vom Franz Biberkopf (1929), pues surge en una época de enorme ebullición política y también de militancia sexodisidente, la Alemania de la República de Weimar. En este artículo, se realizará, en primer lugar, un recorrido por las representaciones de la disidencia sexual en Berlin Alexanderplatz de Alfred Döblin, pensándola, justamente, en el contexto social y político antes mencionado. En segundo lugar, se intentará llevar adelante un análisis de la constitución de las masculinidades heterosexuales en el período. En contraste con esta efervescencia sexual del Berlín de los años veinte, me interesa también pensar la producción de las heteromasculinidades en la relación de los personajes de Franz y Reinhold, a partir de los conceptos de homosociabilidad (SEDGWICK 1998) y melancolía de género (BUTLER 2007).

Retomando a Gayle Rubin (1986), Eve Sedgwick postula el concepto de "male homosocial desire" refiriéndose a la sociabilidad entre varones heterosexuales, pues, según ella, guarda una relación con el deseo reprimido. Según Sedgwick, los vínculos entre hombres están estructurados a partir de la prohibición de la homosexualidad. En este sentido plantea el continuum que va de la homosociabilidad hasta la homosexualidad (SEDGWICK 1985: 1-2). Las relaciones de poder del patriarcado dependen de las relaciones homosociales entre hombres y, de esta forma, de la sublimación del deseo homosexual propia de la homosociabilidad. Así, heterosexualidad y homosexualidad no son binarios sino que forman parte de un continuum que el patriarcado rompe, vuelve discontinuo, a los efectos de sostener el sistema de opresión: "los efectos opresivos sobre las mujeres y los hombres de un sistema cultural en que el deseo intermasculino se hizo fundamentalmente inteligible mediante su desviación hacia relaciones triangulares que implicaban a una mujer" (SEDGWICK 1998: 27), lo que Gayle Rubin (1986) llamó el tráfico de mujeres y que nos permite pensar la particular relación entre Franz y Reinhold en Berlin Alexanderplatz. Se genera así la lógica -o "epistemología", como la llama 
RUBINO, A.R. - Homosociabilidad y disidencia en Berlin Alexanderplatz

Sedgwick- del armario, del silenciamiento y ocultamiento de la sexualidad no heterosexual, "el juego de poder que se ha estructurado alrededor de cuestiones de la visibilidad y la invisibilidad, del silencio y la toma de la palabra, del secreto y del outing (o salida del armario), de la lucha en definitiva por la legitimidad de la instancia que designa y muestra la diferencia" (CÓRDOBA 2005: 51). En este sentido, la homosexualidad "no es un afuera absoluto de la heterosexualidad, sino un afuera interno a su propio funcionamiento y definición" (CÓRDOBA 2005: 50).

De esta forma, "los lazos prescritos de homosociabilidad pueden y deben estar constantemente expuestos a interrogación y escrutinio, dada la posibilidad de su desplazamiento hacia el vínculo homosexual proscrito" (CÓRDOBA 2005: 49). A resultados similares llega Judith Butler (2007) a partir del concepto de melancolía de género. A partir de la idea de melancolía de Freud como la imposibilidad del duelo porque no se reconoce la pérdida, Butler considera que en la identidad heterosexual se alberga un deseo homoerótico elidido desde el comienzo y cuyo duelo no se puede llevar adelante porque no se lo reconoce. Este proceso es, a su vez, producto de las internalizaciones de las normas sociales de género y sexualidad, que siempre son disciplinarias y regulatorias. Para Butler, entonces, la identidad de género resulta "la interiorización de una prohibición" (BUTLER 2007: 147) que exige no sólo "la pérdida de ciertos vínculos sexuales" sino también "que esas pérdidas no sean reconocidas y no sean lloradas" (BUTLER 2001: 150). Entonces, la identificación melancólica de la niña con la madre y el niño con el padre encarna dentro de sí la prohibición y la pérdida no llorada de la carga homosexual (BUTLER 2001: 151):

Si la negación heterosexual de la homosexualidad origina la melancolía y si ésta interviene mediante la incorporación, entonces el amor homosexual no reconocido se salvaguarda desarrollando una identidad de género definida como opuesta. En definitiva, la homosexualidad masculina no reconocida termina en una masculinidad intensificada o afianzada, la cual mantiene lo femenino como lo impensable e innombrable (BUTLER 2007: 157).

Por eso Butler afirma que el género es un efecto de la melancolía (BUTLER 2001: 150) y también que es una cita (BUTLER 2002: 326). El género es una cita obligada de la norma cultural, que no puede disociarse de las relaciones de disciplina, regulación y castigo. En este sentido, los sentimientos de melancolía, de pérdida no llorada, son el costo que acarrean las identidades de género rígidas y no problemáticas, las heterosexualidades estables y las masculinidades hegemónicas.

Centrándome sobre todo en la presencia de elementos sexo-disidentes así como,

Pandaemonium, São Paulo, v. 24, n. 44, set.-dez. 2021, p. 374-399 
RUBINO, A.R. - Homosociabilidad y disidencia en Berlin Alexanderplatz

fundamentalmente, en las relaciones homosociales que se establecen entre el protagonista y su antagonista, me interesa pensar Berlin Alexanderplatz y la gran ciudad en el contexto de la militancia disidente (Schwul y lésbica) de los años veinte en la República de Weimar. Si la adaptación cinematográfica de Fassbinder en 1980 y sus declaraciones abrieron la posibilidad de realizar una lectura queer de la novela de Döblin de un modo en el que antes no había sido posible, ${ }^{2}$ es importante tener en cuenta también que éstas después de Fassbinder se centraron mayoritariamente en la versión e interpretación del director, más que en los elementos presentes ya en el texto de Döblin (ELISSEEVA 2017: 63). En ese sentido, este artículo se centra, justamente, en la novela de Döblin para pensar el contraste entre la cultura sexo-disidente de la República de Weimar y su representación en la novela con la producción de masculinidades heterosexuales, propia de un patriarcado que se veía resquebrajado ante el desafío que implicó la crisis de la masculinidad posterior a la Primera Guerra Mundial.

\section{La novela de gran ciudad}

Alfred Döblin era médico psiquiatra y trabajaba en la parte este de Berlin, una zona básicamente obrera, por lo que tenía pacientes de clase baja. A su vez, su profesión reviste importancia debido a la enorme influencia que el discurso del psicoanálisis tuvo en las vanguardias artísticas con respecto a la ruptura con el sujeto cartesiano. Döblin lo utiliza también en los perfiles de los protagonistas con ciertos elementos de la psiquiatría: Franz y Reinhold. Comprometido políticamente con el socialismo, en su obra confronta anarquismo, socialismo y comunismo con la política vigente. En este sentido, da testimonio bien claro de la confrontación de estas ramas de la izquierda con la extrema derecha, el nacionalsocialismo, que estaba surgiendo.

Berlin Alexanderplatz. Die Geschichte vom Franz Biberkopfes es una de las más importantes novelas vanguardistas de la gran ciudad. Como su doble título lo indica, el personaje central, que cobra más relevancia, es la ciudad de Berlín en sí, la metrópolis, además de su protagonista, Franz Biberkopf. A su vez, se trata de una novela que,

\footnotetext{
${ }^{2}$ Es importante tener en cuenta que las referencias a la novela de Döblin en la obra de Fassbinder no se agotan en la adaptación que realizó en 1980, sino que se pueden rastrear en casi toda su obra, desde las primeras producciones cinematográficas. Para un análisis de la adaptación audiovisual de Fassbinder en 1980, cf. Rubino (2018). Para una profundización en la influencia y las múltiples referencias intermediales en toda la obra cinematográfica del director, cf. Rubino (2020).
}

Pandaemonium, São Paulo, v. 24, n. 44, set.-dez. 2021, p. 374-399 
RUBINO, A.R. - Homosociabilidad y disidencia en Berlin Alexanderplatz

mediante la técnica del montaje, contiene una enorme cantidad de discursos intertextuales e intermediales. Es importante mencionar que el texto de Döblin estaba influenciado por el medio cinematográfico y artístico en general, no sólo por la novedosa técnica del montaje cinematográfico, sino porque también Berlin ya aparecía como motivo del arte contemporáneo en ejemplos clásicos como Metropolis (1926) de Fritz Lang, la película documental Berlin. Die Sinfonie der Großtadt (1927, año del inicio de la redacción de Berlin Alexanderplatz ${ }^{3}$ ) de Walter Ruttmann, o el libro de fotos Berlin (1928) de Mario von Bucovich, que aparece con prefacio del propio Döblin.

La historia de Franz comienza con su salida de la cárcel de Tegel, en donde estuvo cuatro años por el asesinato de Ida. Desde que sale en libertad va a intentar, sin éxito, llevar adelante una existencia honrada, recomponer su vida, ser un ciudadano respetable y honesto. Pero Alemania se encuentra en la mitad de una depresión y crisis económica y es muy difícil sobrevivir y encontrar trabajo honrado. La historia de Franz está estructurada a partir de tres caídas del héroe, tres fracasos en su intento de ser un ciudadano honrado, que se deben a su carácter inocente y confiado. La primera caída se origina cuando comienza una relación con una viuda y Otto Lüders, el tío de Lina, su pareja en ese momento, lo traiciona. Después de una serie de trabajos marginales que consigue y con los que no tiene éxito, conoce a Reinhold, con quien comienza una relación extraña: una amistad basada en el intercambio de mujeres. Cuando Reinhold, que no resiste mucho tiempo con la misma pareja, se cansa de su novia, Franz se encarga de sacársela de encima poniéndose en pareja él. A su vez, Reinhold lo relaciona con la cabeza de una pandilla, Pums, y en la primera participación con ella pierde un brazo porque Reinhold lo tira del auto con el que escapaban. Esta es su segunda caída. Pero sobrevive y Eva le presenta a Mieze con quien comienza una relación y de la que se enamora. Mieze se prostituye para que Franz no tenga que trabajar y pueda cumplir con su meta de ser un ciudadano honrado, aunque esto lo convierta, nuevamente, en un proxeneta. La tercera y definitiva caída se da cuando Reinhold, celoso de esta relación, asesina a Mieze. Después de pasar por un hospital psiquiátrico, Franz se recupera y se convierte en un hombre respetable. Según Dollenmayer (1988), se puede pensar a Franz Biberkopf como un "Everyman", un hombre cualquiera, en el sentido de que la novela deja atrás al héroe clásico y se ocupa de una vida como cualquier otra. Por eso, uno de los elementos intertextuales más importantes va a ser la tragedia clásica. Döblin muestra lo alejado que

\footnotetext{
${ }^{3}$ Sobre las etapas redaccionales de Berlin Alexanderplatz de Döblin, cf. Sander (1998).
}

Pandaemonium, São Paulo, v. 24, n. 44, set.-dez. 2021, p. 374-399 
está en la modernidad el modelo del héroe clásico (SANDER 2004: 156-7). La cita de textos canónicos, a su vez, juega un rol decisivo en la destrucción de lo heroico y lo solemne. La mezcla de citas de la cultura alta y baja provoca una discrepancia que es característica y que produce un efecto cómico, como se puede ver en las parodias a las canciones militares. Otto Keller plantea que la novela de Döblin confronta los puntos básicos del humanismo occidental y del heroísmo y los convierte en una sátira humorística, reflejando y exponiendo el vacío del heroísmo después de la Primera Guerra Mundial (KeLler 1980: 205). Por su parte, Sander comenta que la intertextualidad le permite a Döblin confrontar a su protagonista con "the concept of the hero of classical tragedy and the Prussian-soldierly ideal of masculinity" (SANDER 2004: 151).

A su vez la novela contiene elementos de distintos movimientos de vanguardia, como expresionismo, dadaísmo, surrealismo, futurismo, etc. además de elementos también naturalistas. Se la compara con Ulises $(1922)^{4}$ de James Joyce ${ }^{5}$ y Manhattan Transfer (1925) de John Dos Passos, ${ }^{6}$ que funcionan como antecedentes. ${ }^{7}$

Respecto a la narración, el narrador personal por momentos se dirige al lector, siempre manejando distintos niveles de ironía respecto al propio relato. A diferencia del narrador omnisciente propio de la novela realista, la narración de Berlin Alexanderplatz por momentos deja lugar a la escucha de los ruidos y las voces, los sonidos de la gran ciudad. Es así que junto a la historia del protagonista y de los otros personajes, aparecen historias menores. Encontramos, entonces, tres planos narrativos: la historia de Franz, las historias paralelas de Berlin y las citas de textos que transmiten la impresión de la gran ciudad, cómo es la cultura de Berlin, cómo es la forma de gobierno, la política, el poder legislativo, etc.

En la novela también se registran distintos niveles de lengua (RIBEIRO DE SOUSA 1997: 37) y diferentes discursos: dialecto de Berlin, lenguaje bíblico, canciones infantiles, noticias, escritos administrativos, informes científicos, fórmulas físicas, titulares de periódicos, presentación de empresas, slogans publicitarios, etc. Lo que está presente en

\footnotetext{
${ }^{4}$ Para una discusión sobre la influencia de estos dos textos, si efectivamente los conocía al momento de la redacción de Berlin Alexanderplatz o no, cf. Prangel (1975).

${ }^{5}$ Con la que comparte, fundamentalmente, el uso del fluir de la conciencia, además de tratarse de otra de las novelas más importantes de la gran ciudad.

${ }^{6}$ Particularmente, en el uso novedoso de la técnica de montaje, tomado del cine, así como por la descripción realista de la gran ciudad.

7 En "Krisis des Romans. Zu Döblins Berlin Alexanderplatz" (1930), Walter Benjamin se refiere a Berlin Alexanderplatz para hablar de la crisis de la novela. Cf. Koval (2012 y 2018).
}

Pandaemonium, São Paulo, v. 24, n. 44, set.-dez. 2021, p. 374-399 
RUBINO, A.R. - Homosociabilidad y disidencia en Berlin Alexanderplatz

estos niveles de lengua es la percepción de la realidad. Es muy importante también el hecho de que la atmósfera de la gran ciudad se acompaña también con Leitmotiven bíblicos, utilizados para describir la ciudad, uno de ellos es la puta Babilonia (die Hure Babylon). Como afirma Sander,

Döblin weaves the central theme of the Biberkopf story into a dense fabric of contemporary discourses and intertextual allusions. Over long stretches of text, the digressive montage elements (including literary quotations and parodies, newspaper announcements, weather reports, and collages of popular songs and advertisements) press the main plot into the background and abolish its chronology in favor of simultaneous polyphony. An especially large amount of space is occupied by biblical and mythological montages that implicitly comment upon and transcend the story's events: for example, the Agamemnon myth, the paraphrased stories of Job and Isaac, and quotations from the Apocalypse, which are repeated like a leitmotif (SANDER 2004: 145).

Considerada una Montageroman desde Benjamin en adelante (CORNELSEN 2010: 67), la mezcla de discursos producen la idea de caos y desconexión (CORNELSEN 2009: 251), haciendo difícil al lector establecer nexos (RIBEIRO DE SOUSA 1997: 36). Como dice Ribeiro de Sousa, Berlin no es descrita sino que se impone a través de los discursos como la ciudad de los avances tecnológicos, la velocidad, el progreso desparejo, las máquinas: "A cidade vibra no ritmo do barulho. Nada nela aparece isolado, cada detalhe é apenas um estilhaço, um átomo de sua totalidade que, para ser apresentada, é fragmentada, criando a simultaneidade dos acontecimientos que lhe dão vida" (RIBEIRO DE SOUSA 1997: 40)

En esta mezcla de discursos, el recurso que más claramente se puede identificar en la forma de la novela es el montaje o collage, tomado tanto del cine como de los montajes artísticos propios de las vanguardias de principios del siglo XX. Cornelsen (2010) destaca que ya desde 1913 Döblin venía escribiendo teoría sobre la nueva narrativa y hablaba del Kinostil y el montaje (CORNELSEN 2010: 56-8). El logro de Döblin es querer hacer en la literatura lo que se hacía en las artes plásticas o en el cine. Se trata entonces, de una novela muy compleja desde la intertextualidad (OGASAWA 1996) y la intermedialidad: “A grande cidade é literalmente montada através de um emaranhado de textos que se entrecruzam na história do protagonista Franz Biberkopf' (CORNELSEN 2010: 64). Döblin no sólo utiliza la intertextualidad sino también recursos de otros medios, como el cine, la plástica y la radio. Lo característico de la intertextualidad y el montaje es que las citas y referencias por lo general están en tensión unas con otras, produciendo, más que un discurso coherente y cohesivo, una cacofonía de voces (SANDER 2004: 147). 
RUBINO, A.R. - Homosociabilidad y disidencia en Berlin Alexanderplatz

Según Hilman (1991), se trata de una "history in the making". De hecho, durante y antes de la escritura Döblin recolecta recortes de periódicos de las más divergentes opiniones políticas y los integra dentro de su texto, como comenta Stenzel en su análisis de los manuscritos, lo hace literalmente con tijera y adhesivo (STENZEL 1972: 39-44).

\section{Masculinidades hegemónicas y disidencias sexuales}

Las sexualidades, en general, así como los elementos sexo-disidentes, en particular, tienen una importancia en la novela que no siempre es destacada. Me interesa mencionar algunas cuestiones vinculadas a eso: en primer lugar, la tematización de la persecución políticosexual a la disidencia y, por otro lado, la relación entre Franz y Reinhold que se puede pensar como homosocial en relación también a la puesta en crisis de la masculinidad heterosexual después de la Primera Guerra Mundial.

Es muy interesante revisar el apartado "Lina besorgt es den schwulen Buben" del Libro Segundo. Franz está con Lina, la polaca, su primera pareja en la diégesis de la novela antes de conocer a Reinhold y mantener el intercambio de mujeres con él. Como una de las formas de vida para ser una persona honrada, intenta vender revistas, le ofrecen revistas pornográficas, con dibujos de mujeres y de hombres, destinadas a un público de pornografía pero con discusiones sobre sexualidad que se pueden pensar a partir del contenido político sexo-disidente. Por ejemplo, el vendedor de revistas que se las ofrece le lee un fragmento de "Die Ehelosen": “querer regular la vida sexual de los cónyuges mediante un contrato y establecer al respecto deberes matrimoniales, como prescribe la Ley, significa la esclavitud más abominable e indigna" (1987: 66) [Das Sexualleben der beiden Ehegatten durch einen Vertrag regeln wollen, diesbezüglich eheliche Pflichten zu dekretieren, wie es das Gesetz vorschreibt, bedeutet die scheußlichste und entwürdigendste Sklaverei...” (2002: 97)].

Pero también entre las revistas pornográficas están las disidentes que luchan contra las legislaciones de persecución a las minorías sexuales, como Frauenliebe ${ }^{8}$ y Freundschaft, las que, según el vendedor "no dicen tonterías, sino que luchan. Sí, señor, por los derechos humanos" [“die quatschen nicht, die kämpfen. Jawoll, für Menschenrechte"]. Se trata de la militancia contra el Parágrafo 175 y demás legislaciones

\footnotetext{
${ }^{8}$ Mencionada en Sternweiler (2004), junto a otras publicaciones periódicas disidentes de la época.
} 
de persecución de la homosexualidad. Así es que Franz entra en contacto, aunque muy superficialmente -y escapa de forma rápida-, con los Schwulen Buben: “¿Qué les pasa?». «El artículo 175, por si no lo sabes»” [“»Wo fehlts denen denn?«»Paragraph 175, wenn dus noch nicht weißt«"]. Esa misma noche asiste a una conferencia “en la que Franz podría oír algo sobre la injusticia que sufren diariamente en Alemania un millón de personas. Para poner los pelos de punta" (1987: 67) [“da könnte Franz was hören über das Unrecht, das einer Million Menschen täglich in Deutschland geschieht. Die Haare könnten einem zu Berge stehen" (2002: 99)]. Sin decirle nada a Lina y junto al vendedor asiste al evento. Se trataba de "una pequeña sala donde se sentaban juntos casi todos hombres, en su mayoría muy jóvenes, y algunas mujeres, pero también como parejitas" (1987: 67) [“den kleinen Saal, wo fast lauter Manner beisammen sassen, meist sehr junge, und ein paar Frauen, aber auch als Pärchen (2002: 99)"]. Pero Franz no aguanta mucho tiempo allí y se va, porque no entiende y no puede soportar "tanto maricón junto y él en medio" (1987: 68) [“so viel Schwule auf einem Haufen und er mitten drin (2002: 100)"]. Sin embargo, llega a oír algunas de las pancartas políticas militantes de los derechos de la disidencia sexual:

Lo último que oyó allí dentro fue que el conferenciante hablaba de Chemnitz, donde había una Ordenanza de policía del 27 de noviembre. Los homosexuales no podían ir por la calle ni entrar en los retretes públicos y, si los pescaban, les costaba 30 marcos (1987: $68)^{9}$.

Franz pasa del rechazo a sentir cierto interés. En un primer momento, desconfía del contenido de las revistas, no se siente identificado: "Die schwulen Buben. (...) Leid können einem ja die Jungs tun, aber eigentlich gehn sie mir nichts an.” (99) [“Maricones. (...) La verdad es que esos chicos le dan a uno una lástima, pero en realidad no me importan nada" (67)]. Pero luego de la conferencia, se detiene a leerlas en su casa y llega a reflexionar sobre la situación [“kann über die Schwulen nachdenken” (101)]. Como comenta Elisseeva,

So werden im zweiten Buch unterschiedliche diskursive Facetten der Homosexualität präsentiert und durchgespielt: menschenrechtliche, alltägliche, kosmetisch-medizinische, sentimentale, die am Ende in einem Wort- und Assoziationsspiel aufgelöst werden, um ihre Machart aufzudecken (ELISSEEVA, 2017: 64).

En los años veinte los periódicos proveían un enorme material para el debate sobre el miedo de la población a la homosexualidad. Los homosexuales tenían que lidiar con la

\footnotetext{
${ }^{9}$ „Zuletzt hörte er drin noch den Referenten sprechen von Chemnitz, wo es eine Polizei verordnung gäbe vom November 27. Da dürfen die Gleichgeschlechtigen nicht auf die Straße gehen und nicht in die Be dürfnisanstalten, und wenn sie erwischt werden, kostet es sie 30 Mark“ (2002: 100).
} 
RUBINO, A.R. - Homosociabilidad y disidencia en Berlin Alexanderplatz

hostilidad y el chantaje (SHEA, 2007: 144). Chantaje, suicidios, represiones, escándalos, rechazo familiar, persecuciones policiales, son la otra cara de la liberación sexual de los locos años veinte de la Alemania de la República de Weimar. Es muy importante en este contexto la figura de Magnus Hirschfeld, el más ferviente activista por los derechos de los homosexuales y en contra del parághrafo 175, creador del Wissenschaftlichhumanitäres Komitee en 1897 y del Institut für Sexualwissenschaft en 1919 y colaborador para la realización de la película Anders als die Andern (1919), que denuncia justamente los chantajes que promovía la penalización de la homosexualidad. De este debate de la época también da cuenta la figura de Richard von Krafft-Ebing en cuyo Psychopathia Sexualis (1886), una de las primeras clasificaciones de las perversiones sexuales, incluye a la homosexualidad. Es muy importante el debate sobre el parágrafo 175, pues, por ejemplo, mientras Hirschfeld lo consideraba criminal, la derecha nacional y conservadora lo criticaba y atacaba a él por judío (SHEA 2007: 144). ${ }^{10}$

Mediante la técnica del montaje tenemos el recorte de una revista y una de las historias de persecución homosexual. Se trata de la historia de amor entre un hombre casado, pelado (“Glatzkopf”), y un muchacho ("hübscher Junge”). Se conocen en el Tiergarten, espacio histórico de cruising en Alemania. Dan un paseo tomados del brazo "y entonces el calvo siente el deseo, o el impulso o la concupiscencia, enorme, repentino, de ser muy amable con el joven" (1987: 69)" [“dann hat der Glatzkopf den Wunsch, o den Trieb, o die Begierde, kolossal, im Augenblick, ganz lieb zu dem Jungen zu sein” (2002: 101)]. Ya ha estado con otros muchachos en Tiergarten, pero con éste cae en una trampa:

Y el joven es tan delicado. Que pueda haber algo así «Ven, vamos a un hotelito. Me regalas cinco o diez marcos, estoy sin un céntimo». «Lo que quieras, sol mío». Le regala el billetero entero. Que pueda existir algo así. Eso es lo más bonito de todo (1987: 69). ${ }^{11}$

Pero la habitación tiene agujeros en las puertas por donde son espiados y, luego, amenazados: "Y luego dicen que eso no lo toleran en su hotel, que lo han visto, que no lo puede negar. Y que no lo tolerarán nunca y que debería avergonzarse de seducir jovencitos, lo van a denunciar" (1987: 69) [“Und nachher sagen sie, das dulden sie in ihrem Hotel nicht, das haben sie gesehen, und er kann es nicht leugnen. Und das wurden

\footnotetext{
${ }^{10}$ Para un análisis detallado de las discusiones científicas, políticas y activistas sobre sexualidad en esa época, cf. Weinbacher (2011).

${ }_{11}$ „Und der ist so sanft. Das es so was gibt. «Komm, wir ziehn in ein kleines Hotel. Du schenkst mir funf Mark oder zehn, ich bin ganz abgebrannt.» «Was du willst, meine Sonne.» Er schenkt ihm seine ganze Brieftasche. Das es so was gibt. Das ist das Schönste von allem“"(2002: 101).
}

Pandaemonium, São Paulo, v. 24, n. 44, set.-dez. 2021, p. 374-399 
RUBINO, A.R. - Homosociabilidad y disidencia en Berlin Alexanderplatz

sie nie dulden, und er soll sich schämen, Jungs zu verführen, sie werden ihn anzeigen" (2002: 101-2)]. Glatzkopf piensa en suicidarse, pero finalmente no lo hace y regresa con su familia. Unos meses después le llega la citación judicial por el asunto de los agujeros en el hotel, cuando él está de vacaciones, y se convierte en un escándalo familiar. Así se defiende el acusado:

«Señor juez, ¿qué he hecho yo? No he dado ningún escándalo. He entrado en una habitación y me he encerrado. ¿Qué culpa tengo de que ellos hagan agujeros en la puerta? Y no he hecho nada reprochable». El joven lo confirma. «¿Qué he hecho yo entonces». El calvo llora en su abrigo de piel: «¿He cometido un robo? ¿He asaltado una casa ajena? Sólo he asaltado el corazón de un ser Bueno. Yo lo llamé mi rayo de sol. Y lo era» (1987: 69-70). ${ }^{12}$

Leer estas revistas le trae una pelea con Lina, quien lo quiere dejar porque piensa que él también es así. Luego, Lina se encarga, como una ménade, de devolver las revistas y llevar adelante una riña contra el vendedor. Es interesante pensar aquí el paralelo con la película Anders als die Andern (1919), que también combatía contra el parágrafo 175 y que tematizaba la institucionalización del soborno a los homosexuales. Pero también es importante tener en cuenta la fuerza que tiene esa voz de Glatzkopf que en primera persona defiende su derecho no sólo al amor sexo-disidente queer sino también a las prácticas homosexuales.

La tematización de la persecución a los homosexuales también aparece en el Libro Octavo. Mientras Karl, el hojalatero, se sienta con dos del reformatorio y uno hace dibujos pornográficos, ingresa la policía y se los lleva porque el carpintero parece afeminado:

El carpintero de carros está en la sala con los polis, sabe salir del paso, su dirección está bien, lo único que pasa es que tiene unas manos tan finas para un carpintero de carros, eso no acaba de convencerle a uno de los policías, siempre está moviendo las manos de un lado al otro, pero si no he trabajado desde hace un año, quiere que le diga lo que me parece usted, un marica ( $S c h w u l$ ), un mariposa (warmer Bruder), no sé qué es eso (1987: $367-68) .{ }^{13}$

Así como Schwul, warmen Bruder es una forma eufemística de llamar a los homosexuales y es la razón por la que lo llevan preso. Asimismo, aparece tematizado el travestismo. En el Libro Cuarto, Franz recorre las vidrieras mirando zapatos de mujer y,

\footnotetext{
${ }^{12}$ „«Herr Richter, was hab ich denn gemacht? Ich hab doch kein Argernis erregt. Ich bin auf ein Zimmer gegangen und hab mich eingeschlossen. Was kann ich dafür, wenn die Gucklöcher machen. Und was Strafbares ist nicht passiert.» Der Junge bestätigt es. «Also was hab ich gemacht?» Der Glatzkopf im Pelz weint: «Hab ich gestohlen? Hab ich einen Einbruch begangen? Ich bin nur in das Herz eines lieben Menschen eingebrochen. Ich habe ihm gesagt: mein Sonnen schein. Und das war er.)" (2002: 102-3).

13 „Der Stellmacher steht im Wachraum bei den Schupos, der kann sich richtig rausreden, seine Adresse stimmt, bloß daß er so weiche Hände für einen Stellmacher hat, das leuchtet dem einen Bullen nicht ein, der dreht immer seine Hände hin und her, aber ich hab ja ein ganzes Jahr keine Arbeit, soll ich Ihnen sagen, wofür ich Sie halte, für einen Schwulen, für een warmen Bruder, weiß ja gar nicht, was det is“ (2002: 544).
}

Pandaemonium, São Paulo, v. 24, n. 44, set.-dez. 2021, p. 374-399 
mediante la técnica del montaje, se incrusta una microhistoria de gente de Berlin:

El ridículo de Lissarek, el de Bohemia, el viejo de los grandes agujeros en la nariz que estaba en Tegel, hacía que su mujer, o la que se hacía pasar por ella, le llevara cada tantas semanas un par de bonitas medias de seda, un par nuevo y un par viejo. Para partirse de risa. Aunque ella tuviera que robarlas él tenía que tenerlas. Una vez lo pescaron con las medias en sus piernas roñosas, menudo inútil, se miraba las piernas y se excitaba y se le ponían las orejas coloradas, para partirse de risa (1987: 126). ${ }^{14}$

Además, también por montaje de historias y de publicidades y de distintas voces de la ciudad, después de la historia del pelado leída en la revista, leemos avances en cosmética y medicina destinados a la comunidad travesti de Berlin, probablemente parte de las mismas publicaciones:

Travestidos, después de experimentos de muchos años he encontrado un remedio radical para la barba, incluidas las raíces. Cualquier parte del cuerpo puede ser depilada. Al mismo tiempo he descubierto la forma de conseguir, en tiempo increíblemente breve, un verdadero pecho femenino. Sin medicamentos, un remedio inofensivo absolutamente seguro. Yo mismo soy la prueba. Libertad para el amor en todos los frentes... (1987: 70). ${ }^{15}$

Lejos de ser una invención de Fassbinder en los ochenta, lo que el cineasta viene a poner en evidencia es el fuerte contenido sexual y disidente que ya estaba presente en la novela, fundamentalmente por el hecho de presentar un montaje de voces y discursos contradictorios, que nos generan la sensación de tensión entre diferentes perspectivas, reclamos y oscurecimientos. Como comenta Elisseeva, "Diese zahlreichen expliziten Erwähnungen von Homosexualität in unterschiedlichen Kontexten des Romans zeugen davon, dass der Gegenstand für den Text von merklicher Bedeutung erscheint" (ELISSEEVA, 2017: 64).

\section{Relaciones homosociales entre Franz y Reinhold}

Uno de los aspectos fundamentales para pensar la sexualidad en Berlin Alexanderplatz está dado por la relación entre Biberkopf y Reinhold, que podemos pensar a partir del

\footnotetext{
${ }^{14}$ „Der affige Lissarek, der Böhme, der alte Kerl mit den grossen Nasenlöchern draußen in Tegel, der ließ sich von seiner Frau, oder was sich dafür ausgab, alle paar Wochen ein Paar schöne seidene Strumpfe bringen, ein Paar neue und ein Paar alte. Ist zum Piepen. Und wenn sie sie stehlen sollte, er musste sie haben. Einmal haben sie ihn erwischt, wie er die Strumpfe anhatte auf seine dreckige Beine, son Nulpe, und kuckt sich nun seine Beine an und geilt sich dran uff und hat rote Ohren, der Kerl, zum Piepen“ (2002: 184-5).

15 „Transvestiten, nach jahrelangen Experimenten fand ich endlich ein Radikalmittel gegen Bartstoppeln mit Wurzeln. Jeder Körperteil kann enthaart werden. Gleichzeitig entdeckte ich den Weg, in erstaunlich kurzer Zeit eine echte weibliche Brust zu erzielen. Keine Medikamente, absolut sicheres unschädliches Mittel. Beweis: ich selbst. Freiheit für die Liebe auf der ganzen Front“ (2002: 103). En la edición en español se traduce „Freiheit für die Liebe auf der ganzen Front“ por “Amor libre en toda la línea” (1987: 70). Creo que una versión más literal como "Libertad parea el amor" resulta aquí más significativa.
}

Pandaemonium, São Paulo, v. 24, n. 44, set.-dez. 2021, p. 374-399 
RUBINO, A.R. - Homosociabilidad y disidencia en Berlin Alexanderplatz

concepto de homosociabilidad de Sedgwick (1998) -que lo analiza en las novelas del siglo XIX y XX-, así como los de melancolía de género (BUTLER 2007), tráfico de mujeres (RUBIN 1986) y terror anal (PRECIADO 2009). Según esta perspectiva, el heteropatriarcado se sostiene en la sublimación del deseo homosexual mediante las relaciones de camaradería entre hombres heterosexuales. De esta forma, se puede pensar la violencia y agresividad contra la mujer así como su uso como objeto o como bien de mercado, que en Berlin Alexanderplatz aparece claramente simbolizado en el hecho de que casi todas las figuras femeninas sean prostitutas y, fundamentalmente, en la relación de Franz y Reinhold, basada en el intercambio de mujeres.

Podríamos preguntarnos, entonces, qué importancia reviste en este contexto la cultura Schwul tematizada en la novela de Döblin -por ejemplo, esas historias de relaciones homosexuales y la fascinación de Franz ante lo que lee en la revista, casi al principio de la novela, en el Libro Segundo-, así como cuál es el marco que ofrece para pensar la masculinidad de Franz y la relación posterior con Reinhold. Quizá se puede pensar en una homosexualidad reprimida. De hecho algunos críticos han sostenido esto, en tanto otros han rechazado esta idea (Elisseeva 2017: 63). Pero lo cierto es que la novela, más que una represión de la homosexualidad -quizás más evidente en el caso de Reinhold-, da cuenta de la heteromasculinidad hegemónica como una producción y no como algo del orden de lo natural, lo que tiene, además, una importancia en el contexto de la posguerra. Se trata de pensar, en todo caso, esa represión no en sentido individual, personal, del personaje, sino como constitución social de un sistema patriarcal, que entendemos mediante los conceptos de homosociabilidad y melancolía de género.

En este sentido, es interesante pensar cómo lo primero que Franz hace al salir de la cárcel es buscar una prostituta para tener relaciones sexuales. El espacio de la cárcel, a su vez, reviste un carácter homoerótico que pone en peligro las masculinidades heterosexuales, como se concretará más adelante cuando sea Reinhold el que tenga una historia de amor homosexual en la cárcel. Los intentos de Franz de recuperar su masculinidad heterosexual con una prostituta terminan en fracaso debido a la impotencia. La novela nos ofrece, después de cada intento fallido, recortes de explicaciones científicas sobre las posibles causas, médicas y psicológicas, de la impotencia, así como slogans publicitarios de posibles soluciones al problema. Para volver a ser un ser humano, después de ser un reo, Franz debe recuperar su masculinidad. Si no logra concretar una relación sexual con una mujer, no puede considerarse un hombre. Es por eso que luego de este 
intento visita a Minna, la hermana de Ida, la mujer a la que asesinó. Y la viola de forma violenta. Sólo después de que viola a Minna Franz recupera su masculinidad, su virilidad, la que será puesta nuevamente en jaque cuando pierda su brazo derecho. Pero en este caso, con el que se abre la novela, vuelve a ser un hombre en todos los sentidos y lo festeja cantando canciones de triunfo, de guerra.

Él luchó para ponerse en pie, se rió y se retorció de felicidad, de placer, de beatitud. ¿Qué tocan las trompetas? Adelante los húsares, ¡aleluya! ¡Franz Biberkopf ha vuelto! ¡Fran Biberkopf está libre! ¡Franz Biberkopf está aquí! Se ha subido los pantalones, saltaba sobre una pierna y sobre la otra (...). «Minna, mi pequeña Minna, no seas así, estoy tan contento, otra vez soy un ser humano» (...) «iTodo Franz, todo Franz! ¡Franz ha vuelto a la vida, Franz está aquí otra vez!» (1987: 35). ${ }^{16}$

Después de la violación de Minna, Franz festeja que nuevamente es un hombre, un ser humano (ich bin doch wieder ein Mensch), en los dos sentidos que "hombre" tiene en español, pues no sólo recupera su virilidad, su masculinidad y, con ella, su lugar de varón patriarcal, dominante, agresivo y violento, sino también vuelve a ser un ser humano, ein Mensch. Como afirma Elsaesser,

Identity is here asserted in the mode of phallic masculinity. But making love to the double of the woman he has killed, reveals a possibly even more crippling 'inadequacy', circumscribing and prescribing the precarious terms of his new-found identity (ELSAESSER 1996: 222).

Luego comenzará una relación con la polaca Lina, que terminará a raíz de la relación con la viuda y de la traición de Otto Lüders, el tío de Lina, que constituye la primera caída del (anti)héroe moderno. Erika Kuhlman comenta cómo después de la Primera Guerra Mundial, el gobierno y los medios sentaron las bases para el regreso de los hombres como heroicos y dominantes, volviendo a sus roles en un sistema patriarcal intacto, después de la devastación de la guerra (KuHLMAn 2008: 139-40). Según Rentschler,

Döblin's novel was written at time when a widespread war nostalgia was the rage in Germany, an attempt to restore the lost virility of life at the front, precisely at a moment when the fragmentation of political life made ir hard for people to discern exactly where the front lay. Recollections of the war and common experience with other men something evoked continually in Franz's singing of military songs- granted one an intact psychic identity, a remembrance of a period when things were clear-cut and one felt meaningfully engaged in a larger struggle. Döblin's novel reflects the power of these male fantasies during the late 1920s in Weimar Germany. Fassbinder's film goes further: it

\footnotetext{
16 "Er krabbelte hoch, lachte und drehte sich vor Glück, vor Wonne, vor Seligkeit. Was blasen die Trompeten, Husaren heraus, halleluja! Franz Biberkopf ist wieder da! Franz ist entlassen! Franz Biberkopf ist frei! Die Hosen hatte er hochgezogen, humpelte von einem Bein aufs andere. (...) «Minna, Minnaken, nu jieb dir doch, ich bin so froh, ich bin doch wieder ein Mensch, Minnaken.» (...) «Allens Franz, allens Franz! Franz ist wieder lebendig, Franz ist wieder da!»" (2002: 51).
}

Pandaemonium, São Paulo, v. 24, n. 44, set.-dez. 2021, p. 374-399 
RUBINO, A.R. - Homosociabilidad y disidencia en Berlin Alexanderplatz

problematizes them (RENTSCHLER 1985: 207).

A pesar de la experiencia de la guerra y del rol de las mujeres durante ésta, los hombres regresaron a sus roles de machos dominantes. Asimismo, se generó un miedo en la población debido a que la finalización de la guerra generara un caos sexual, los soldados que regresaban eran sospechados de anormales y de desviados sexuales. Como afirma Crouthamel en su estudio sobre las masculinidades después de la guerra,

Though a "new" man had emerged from the trenches, one who could show "feminine" emotions while maintaining the steel- nerved, masculine image, the image of the "effeminate", weak, or homosexual man still caused as much anxiety as it had before 1914. Ironically, it was returning veterans who came under suspicion (CROUTHAMEL 2014: 149).

Resulta interesante pensar, en este sentido, la relación entre Franz y Reinhold, en donde se puede considerar que la extrema violencia de ambos para con las mujeres, así como el contrato de intercambio de mujeres que establecen, guarda relación con la puesta en crisis de las masculinidades después de la guerra. El deseo homosexual debía ser sublimado en favor de los lazos de camaradería patriarcal. La relación entre Franz y Reinhold está claramente marcada como homoerótica. Sin embargo ninguno de los dos reconoce el deseo sexual hacia el otro. Hay que esperar hasta casi el final de la novela para que Reinhold, una vez en la cárcel, descubra su amor hacia los hombres. Pero ya desde su aparición en el Libro Quinto, Franz siente una extraña fascinación hacia él

A ese de amarillo que le señalaba Meck llevaba observándolo Franz toda la noche. Se sentía poderosamente atraído hacia él. (...) La nariz, Franz la contempló con atención y muchas veces, era corta, chata, firmemente plantada (...) Franz no lo perdía de vista. Qué ojos más tristes tenía el tipo (1987: 174-175). ${ }^{17}$

Desde el principio la relación que establecen Franz y Reinhold se basa en el intercambio de mujeres. Reinhold no soporta mucho tiempo con una mujer, siempre tiene que cambiarla por una nueva, pero no puede deshacerse de ellas, así que se las pasa a Franz. Así se intercambian a Fränze, Cilly y Trude.

En primer término, Reinhold le ofrece pasarle a su novia Fränze, porque él ya está con otra, Cilly, a quien luego cambiará a su vez por Trude y se la pasará a Franz. De esta forma se establece una relación homosocial entre ambos, a partir del intercambio de mujeres como forma de sublimar ese deseo homosexual imposible. Las mujeres devienen

\footnotetext{
17 „Diesen Gelben, den ihm Meck bezeichnete, beobachtete Franz den ganzen langen Abend. Franz fühlte sich mächtig von ihm angezogen (...) Die Nase, Franz betrachtete ihn genau und oft, die Nase war kurz, stumpf, sachlich aufgesetzt. (...) Franz hielt ihn mit den Augen fest. Was der Kerl für traurige Augen hat" (2002: 255).
} 
RUBINO, A.R. - Homosociabilidad y disidencia en Berlin Alexanderplatz

así un bien de intercambio, quieren deshacerse de ellas por cuestiones ridículas, Fränze, por ejemplo no tiene ropas de invierno, por lo tanto la tendrá que dejar cuando éste llegue. Pero es una situación que Reinhold no soporta, hay algo en esa forma de relacionarse con las mujeres que le produce insatisfacción y que se puede pensar como una homosexualidad reprimida. Así se lo expresa a Franz en la charla que tienen cuando van al Ejército de Salvación:

Quiero librarme de las mujeres, Franz, no quiero seguir (...) ¿Crees que me divierte venir otra vez a ti la semana que viene y decirte que te lleves a la Trude, a la rubia? No, sobre esa base (...). Déjame en paz con las mujeres. ¿Y si yo no quiero, Franz? (1987: 180-1). ${ }^{18}$

Si el patriarcado es un sistema que oprime a las mujeres, que las convierte en bienes de mercado, de intercambio, también hay una opresión a los hombres, que implica que deben adoptar su lugar de superioridad, reprimiendo la posibilidad del deseo homosexual. Así se puede explicar la extraña relación que Reinhold establece con las mujeres, se vuelve loco por ellas pero las deja fácilmente y de forma cobarde. La forma de tapar su insatisfacción heterosexual es cambiando de mujer cada cuatro semanas:

Ya sabes que las mujeres me hartan rápidamente. Tú lo sabes, oye. Al cabo de cuatro semanas se acabó. Por qué, no lo sé. No me gustan ya. Y antes ando loco por alguna, tendrías que verme, completamente loco, para encerrarme sin más en una celda acolchada, así de loco. Y luego: nada, que se vaya, no puedo verla, pagaría dinero para no verla (1987: 181). ${ }^{19}$

Tal como afirma Butler, cuanto una masculinidad heterosexual más exacerbada se manifiesta, es también mayor el deseo homosexual elidido que alberga. Tal es la carga que Reinhold tiene que soportar, que lo convierte en el antagonista y en el villano. Se trata de hombres, tanto el caso de Reinhold como de Franz, castrados de ano, en términos de Preciado (2009). En “Terror anal. Apuntes sobre los primeros días de la revolución sexual", Paul B. Preciado invierte la idea de castración freudiana, la tuerce, para considerar que ésta pone al falo en el centro de lo humano. Reubicando al ano en el lugar central $^{20}$, Preciado convierte a la heteromasculinidad en una castración, en una falta: “el

\footnotetext{
18 ,»Ich will von den Weibern los, Franz, ich will nicht mehr. (...) Meinste denn, es macht mir Spaß, nächste Woche wieder zu dir zu kommen, und du sollst mir die Trude, die blonde, abnehmen! Nee, uff die Basis Laß mich zufrieden mit die Weiber. Wenn ich aber nicht will, Franz?«“(2002: 265).

19, ,»Weißt doch, daß mir die Weiber so rasch über werden. Siehst es ja, Mensch. Nach vier Wochen, dann ist aus. Warum, weeß ich nicht. Mag sie nicht mehr. Und vorher bin ich verrückt nach einer, müßtest mich mal sehen, total verrückt, direkt zum Einsperren in die Gummizelle, so verrückt. Und nachher: nischt, raus muß sie, kann sie nicht sehen, könnte noch Geld hinterherwerfen, wenn ich sie bloß nicht sehe«" (2002: 265-6)

${ }^{20}$ De todas formas, Preciado aclara que no se trata sólo del ano sino de una reterritorialización -con su consecuente desterritorialización del falo- de todo el cuerpo, a su vez, entendido en un sentido amplio que incluye todo lo protésico: "No se trata de hacer del ano un nuevo centro, sino de poner en marcha un proceso de desjerarquización y descentralización que haría de cualquier otro órgano, orificio o poro, un posible
} 
RUBINO, A.R. - Homosociabilidad y disidencia en Berlin Alexanderplatz

ano cerrado es el precio que el cuerpo paga al régimen heterosexual por el privilegio de su masculinidad" (Preciado 2009: 136). En este sentido, la (hetero)masculinidad normativa rechaza toda posibilidad de placer que provenga del ano. Y es esa castración lo que define, justamente, la masculinidad heterosexual hegemónica como una producción y no como lo dado naturalmente:

Puesto a disposición de los poderes públicos, el ano fue cosido, cerrado, sellado. Así nació el cuerpo privado (...). Así nacieron los hombres heterosexuales a finales del siglo XIX: son cuerpos castrados de ano. Aunque se presenten como jefes y vencedores son, en realidad, cuerpos heridos, maltratados (PRECIADO 2009: 136).

\section{Pérdida del brazo y castración}

La segunda caída que el protagonista va a sufrir es la pérdida del brazo derecho, ocasionada por el accidente provocado por Reinhold. Después de participar - de forma involuntaria- de un robo, Reinhold lo tira del auto en el que escapaban. Su deseo hacia Franz se vuelve tan insostenible que debe terminar con él. Pero éste sobrevive y sólo pierde el brazo derecho, aunque se trate de un símbolo de este tipo de masculinidad, de la fuerza de trabajo, de la violencia y agresividad hacia las mujeres: "Franz's amputed limb becomes a monument for a lost world war as well as the embodiment of a forthcoming dismemberment" (RENTSCHLER 1985: 206). Con el brazo derecho, Franz pierde, de forma simbólica, su virilidad, la que había recuperado por medio de la violación al inicio de la novela. Como comenta Shea,

Franz defines his masculinity by means of his arm. If feminity is characterized by passivity and prayer (a plea, as it were, to have something done to/for you), masculinity is defined as action, and there are scarcely any more potent symbols for action than hands and arms (SHEA 2007: 152).

La pérdida del brazo puede pensarse, en este sentido, como una castración. También a raíz del accidente se termina el pacto heteromasculino entre Franz y Reinhold que simboliza el lugar de la mujer en el patriarcado. Se trata de un amor, en términos de cómo lo piensa Fassbinder, de esos raros que no se dan mucho (FASSBINDER 2002, 196). Sin embargo, luego del accidente, no le guarda rencor, no lo denuncia ni quiere vengarse. No hace nada en su contra sino que, por el contrario, lo va a visitar, pues la fascinación que sentía por él sigue intacta. Así lo explica Elsaesser:

biopuerto anal" (PRECIADO 2009: 171). Esto también se relaciona con el análisis que hace de la mano masturbadora y su relación con el dildo en Manifiesto Contrasexual (PRECIADO 2002).

Pandaemonium, São Paulo, v. 24, n. 44, set.-dez. 2021, p. 374-399 
RUBINO, A.R. - Homosociabilidad y disidencia en Berlin Alexanderplatz

This is the narrative's major provocation, because at first sight it is so undermotivated: we never quite understand why Reinhold did push Franz from the speeding car, and secondly, we never learn from Franz why he is so ready to forget, and so anxious to forgive (ELSAESSER 1996: 226).

Es como si se tratara de una demostración de amor. Claro que de este amor no sólo prohibido, sino imposible de pensar como tal. Por eso, decide visitarlo. Es interesante pensar la visita de Franz a Reinhold después del accidente, ya que ambos discuten sobre las posibilidades de usar una prótesis o un relleno para que no se note el brazo faltante. Esta escena se puede entender como homoerótica, no sólo en el sentido del contacto corporal entre ellos, sino también porque Reinhold le pide ver el muñón y hay en esta visión un componente de asco y de placer al mismo tiempo. De cualquier forma, si pensamos la pérdida del brazo como una especie de castración simbólica de Franz, la necesidad de buscarle una forma de disimularlo se trata también del interés de Reinhold por recuperar la masculinidad perdida de su amigo:

y entonces Reinhold le dice bajo, muy bajo: «Me gustaría, me gustaría alguna vez, Franz, me gustaría ver alguna vez tu herida». Que por ese buen chíndarada búndarada. Entonces Franz Biberkopf - eso es- se abre la chaqueta, muestra el muñón con la manga de la camisa y Reinhold tuerce el gesto: tiene un aspecto repulsivo, Franz se cierra la chaqueta: «Antes era peor». Y entonces Reinhold sigue mirando a su Franz, que no dice nada ni puede hacer nada y está gordo como un cerdo y no puede abrir la boca, y Reinhold tiene que seguir sonriéndole forzadamente y no puede dejarlo (1987: 297). ${ }^{21}$

Su amor hacia Reinhold, después del accidente y de este encuentro, sigue intacto, incluso es aún mayor, lo que siente por él es cariño, amor:

$\mathrm{Y}$ en su fuero interno siente cariño, mientras baila con Eva, siente cariño por dos personas: la primera es su Mieze, a la que le gustaría tener allí, y la segunda es... Reinhold. Pero no se atreve a decirlo. Durante toda esa noche estupenda, en la que baila con ésta y aquélla y la de más allá, siente cariño por esos dos que no están, y es feliz con ellos (1987: 301). ${ }^{22}$

Franz ama a dos personas, Mieze y Reinhold. Y este amor traerá su ruina, su tercera y definitiva caída, el asesinato de Mieze por parte de Reinhold. Tanto matar a Mieze como intentar asesinar a Franz constituyen para Reinhold dos intentos de aniquilar una parte de sí mismo que no puede reconocer, su deseo homosexual: “by killing Mieze,

\footnotetext{
${ }^{21}$ „Und dann sagt Reinhold leise, leise: »Ick, ick möcht mal, Franz, ick möcht mal deine Wunde sehen. « Ei bloß wegen dem Tschingdarada bumdarada. Da schlägt Franz Biberkopf - das ist es - die Jacke auf, zeigt den Stumpf mit dem Hemdärmel, Reinhold verzerrt das Gesicht: sieht eklig aus, Franz schlägt die Jacke zu: »Früher wars schlimmer. « Und dann kuckt Reinhold weiter seinen Franz an, der nichts sagt und nichts kann und ist so dick wie ein Schwein und kann nicht das Maul aufmachen, und Reinhold muß den weiter begrinsen und hört nicht auf" (2002: 435).

${ }^{22}$ „Und am innigsten liebt er, während er mit Eva tanzt, liebt er zwei: die eine ist seine Mieze, die er gern da hätte, der andere ist - Reinhold. Aber er wagt es nicht zu sagen. Die ganze herrliche Nacht, wo er tanzt mit der und jener, liebt er diese beiden, die nicht da sind, und ist glücklich mit ihnen“" (2002: 441).
}

Pandaemonium, São Paulo, v. 24, n. 44, set.-dez. 2021, p. 374-399 
Reinhold embodies Franz's darkest, most hidden wishes, which are projected into him through Franz's fantasy of Reinhold being also a former Tegel inmate" (COATES 2012: 406). Recién hacia el final de la novela, en el último libro, esta posibilidad se va a concretar, cuando Reinhold establece una relación sexo-afectiva en la cárcel con Konrad. Nuevamente aquí la cárcel deviene un lugar utópico en donde la posibilidad de llevar a la práctica el deseo homosexual se pone de manifiesto, aunque sólo en el tiempo y espacio de la cárcel, como ocurriera en El beso de la mujer araña (1976), de Manuel Puig.

Y entonces Reinhold se mete en un lío él solo. Durante toda su vida, las mujeres le trajeron dichas y desdichas, y el amor hará ahora que se rompa el cuello. (...). Y como está allí tanto tiempo (...) se hace amigo de uno especialista en robos con fractura que está también en Brandemburgo por primera vez y a quien van a soltar en marzo. (...) luego se convierten en amigos íntimos y verdaderos, algo que Reinhold no había tenido nunca y, aunque no se trate de ninguna mujer, sino sólo de un muchacho, es muy bonito, y Reinhold se siente contento en la prisión de Brandemburgo (...). La pena es que el chico tenga que marcharse pronto (1987: 416-7). ${ }^{23}$

El amor por un muchacho, el que finalmente descubre en la prisión, es el que lo va a llevar a la ruina. Encarcelado con nombre falso por un delito menor, Reinhold es buscado por el asesinato de Mieze. Por amor, confiesa su verdadera identidad a Konrad, quien al salir de la prisión lo denuncia a cambio de la recompensa. De esta manera, hacia el final de la novela, se pone de manifiesto la concreción de la homosexualidad que estaba reprimida en Reinhold. En estos términos, la violencia contra la mujer y su uso como bien de cambio se pueden pensar como parte de un sistema patriarcal que no sólo somete a la mujer sino que, para esto, necesita de la sublimación del deseo homosexual. ${ }^{24}$

\section{Eva y Mieze}

Según el análisis feminista que realiza María Tatar (1992), pensar la novela como el estudio de la historia de un hombre y la ciudad resulta reductivo porque se está evitando

\footnotetext{
${ }^{23}$ „Und dann legt sich unser Reinhold allein rein. Die Weiber brachten ihm zeit seines Lebens Unglück und Glück, die Liebe bricht ihm jetzt auch das Genick. (...) Und wie er so länger sitzt und (...), da hängt er sich an einen Menschen, einen Einbrecher, der auch zum erstenmal in Brandenburg ist und der im März zur Entlassung kommen soll. (...), dann werden sie ganz innig und richtige Freunde, wies Reinhold noch nie gehabt hat, und wenns auch kein Weib ist, sondern bloß ein Junge, es ist doch schön, und Reinhold freut sich im Zuchthaus von Brandenburg (...). Bloß schade ist es, daß der Junge bald fort muß“ (2002: 617).

${ }^{24}$ Tanto Shea (2007) como Crouthamel (2014) comentan la preocupación y debate público sobre la desviación sexual de los soldados que volvían de la guerra y la amenaza que significaba para la familia burguesa, además de la crisis económica de la República de Weimar y el apogeo de los espectáculos sexuales, que hacía que muchas mujeres de clase media se dedicaran a la prostitución: "The war experience seemed to have rendered obsolete the notion of this strict bifurcation between emotional and sexual expressions of love between men" (CROUTHAMEL 2014: 167).
}

Pandaemonium, São Paulo, v. 24, n. 44, set.-dez. 2021, p. 374-399 
RUBINO, A.R. - Homosociabilidad y disidencia en Berlin Alexanderplatz

una cuestión fundamental: la violencia ejercida sobre el cuerpo de la mujer así como la construcción de la figura de la mujer como víctima. Dejando de lado la ansiedad y la inestabilidad que marcan al protagonista, según Tatar, la crítica se ha centrado en la integridad psíquica y la integración social que logra al final, pero Biberkopf "becomes a figure who has established a new, positive masculine identity in the wake of one asault after another on the female body" (TATAR 1992: 136). Tatar sostiene que en la novela sobresalen sólo dos figuras de la agencia femenina, en contraste al resto de las mujeres que son representadas como víctimas de la violencia, en donde los agentes son hombres. Se trata de la puta de Babilonia y de Clitemnestra, ambas representadas negativamente (TATAR 1992: 147).

Sin embargo, resulta muy interesante pensar un caso contrapuesto al de la relación Biberkopf/Reinhold: el de Eva y Mieze. Eva puede ser considerada una figura de mujer diferente a las demás. Es una mujer emancipada a partir de la prostitución (KARLAVARISBREMER 1985). No es sometida por su gigoló pero tampoco por el matrimonio. Es ella quien le presenta a Mieze a Franz. En el Libro Sexto ambas piensan la idea de tener un hijo de Franz y que la madre biológica sea Eva, pero que el hijo sea de los tres. ${ }^{25} \mathrm{Se}$ plantea, así, la posibilidad de una familia disidente:

Sonja, sin embargo, hace algo muy distinto de lo que esperaba Eva. Sonja grita, tiene el rostro desencajado, aparta al monito del pecho de Eva y la abraza violenta, feliz, beatífica y tiernamente a Eva, que no comprende nada y vuelve el rostro, porque Sonja no deja de besarla. "Anda, Eva, anda. No estoy enfadada, me alegro de que él te guste. Dime, ¿cuánto te gusta? Te gustaría tener un hijo suyo, pues díselo» Eva consigue librarse de Sonja. «Tú estás loca mujer. Oye, ¿qué te pasa? Dime la verdad: ¿quieres traspasármelo?» «No, por qué, quiero conservarlo, es mi Franz. Pero tú eres mi Eva» (1987: 277). ${ }^{26}$

Hay que pensar también que, si bien Mieze es una prostituta como casi todos los personajes femeninos de la novela, es la pareja de Franz después de que éste pierde su brazo derecho y, con él, parte de su masculinidad, al menos en sentido simbólico. Desde esta perspectiva, no es menor pensar en la importancia de que Mieze se convierta en la proveedora del hogar, ocupando el lugar asignado al hombre, y comprometiéndose a

\footnotetext{
${ }^{25}$ Algo similar ocurre en la novela de la misma época Der fromme Tanz (1925) de Klaus Mann, en donde se plantea la posibilidad de tener un hijo producto de una relación entre tres personas.

26 "Sonja tut aber etwas ganz anderes, als Eva glaubt. Sonja kreischt, hat ein aufgerissenes Gesicht, schiebt das Äffchen von Evas Brust weg und umarmt heftig, glücklich, selig, wonnig die Eva, die nicht versteht und das Gesicht wegdreht, denn Sonja will sie immer küssen. «Na komm doch, Eva, komm doch. Ich bin doch nicht böse, ich freue mich, dass du ihn magst. Sag mal, wie gern hast du ihn? Ein Kind mochtst du von ihm, na, sags ihm doch.» Eva kriegt es fertig, das Mädel von sich wegzudrangen. «Bist du verrückt, Mensch. Sag mal blos, Sonja, was ist mit dir? Sag mal aufs Wort: willste ihn mir zuschanzen?» «Nee, warum denn, ick mocht ihn doch behalten, det is mein Franz. Aber du bist doch meine Eva.» «Wat bin ich?» «Meine Eva, meine Eva»" (2002: 405-6).
}

Pandaemonium, São Paulo, v. 24, n. 44, set.-dez. 2021, p. 374-399 
RUBINO, A.R. - Homosociabilidad y disidencia en Berlin Alexanderplatz

mantenerlo para que él no tenga que trabajar y, con ello, pueda llevar una vida honrada. Eva, por su parte, está en pareja con Herbert, pero tiene también sus amantes/clientes. Lo interesante es que es ella quien decide, no se somete al intercambio de mujeres, no forma parte de ese tráfico patriarcal. Ambas constituyen, así, en distinta medida, figuras de mujeres fálicas. La escena en la que Eva y Mieze deciden tener un hijo de Franz está marcada, claramente, como homoerótica:

Y Eva no puede defenderse, Sonja la besa en la boca, en la nariz, las orejas, el cuello; Eva se queda quieta, luego, cuando Sonja entierra su rostro en el pecho de ella, le levanta la cabeza con fuerza: «Tú eres tortillera». «Qué va», tartamudea la otra, librando otra vez su cabeza de las manos de Eva, y apoyándola contra su rostro, «me gustas, no lo sabía. Antes, cuando dijiste que querías un hijo suyo...». «Bueno, ¿y qué, mujer? ¿Te sentó mal?». «No. Eva. No sé». Y Sonja tiene el rostro encendido y mira a Eva desde abajo: «¿De verdad querrías tener un hijo suyo». «Pero, ¿qué te pasa?». «¿Lo querrías?». «No, era hablar por hablar». «Sí, quieres uno, no hablas por hablar, lo quieres, lo quieres». Y otra vez se entierra Sonja en el pecho de Eva y la aprieta contra sí, ronroneando con delicia: «es tan bonito que quieras un hijo suyo, ay, es tan bonito, soy tan feliz, ay, qué feliz soy»

Eva lleva a Sonja a la habitación de al lado, la echa en el diván: «Tú eres tortillera, mujer». «No, no soy tortillera, nunca he tocado a ninguna». «Pues a mí te gustaría». «Sí, porque me gustas y porque quieres tener un hijo suyo. Y lo tendrás» $(1987: 277-8) .{ }^{27}$

Según María Tatar (1992), la crítica se ha ocupado de dos aspectos en la obra de Döblin, la técnica del montaje y la historia de Biberkopf pensada como Bildungsroman. ${ }^{28}$ En este sentido, se ha intentado dar orden y coherencia al estilo fragmentario y contradictorio del montaje de la novela, por un lado y, por el otro, se ha pensado el final como el momento de iluminación del protagonista, cuando finalmente se convierte en una persona honrada. Sin embargo, Tatar llama la atención sobre la desexualización del

\footnotetext{
27 „Und Eva kann sich nicht wehren, Sonja küss sie auf Mund, Nase, Ohren, Nacken; Eva halt still, dann, wie Sonja ihr Gesicht in Evas Brust wühlt, hebt Eva stark Sonjas Kopf hoch: «Mensch, du bist schwul.» «Gar nicht», stammelt die und entzieht wieder ihren Kopf Evas Händen, legt ihn an Evas Gesicht, «ich hab dich gern, ich hab das noch gar nicht gewusst. Vorhin, wie du sagst, du willst von ihm ein Kind -.» «Na, was denn, Mensch? Da biste tückisch geworden?» «Nee, Eva. Ich wees doch nicht.» Und Sonja hat ein glutrotes Gesicht und sieht die Eva von unten an: «Du mochst wirklich von ihm ein Kind?» «Wat is denn mit dir?» «Mochste von ihm eins?» «Nee, ich habs bloss gesagt.» «Ja, du willst doch eins, du sagst bloss so, du willst, du willst.» Und wie der wühlt sich Sonja an Evas Brust und presst Eva an sich und summt wonnig: «Das ist so schon, das du von ihm ein Kind willst, ach, ist das schon, ich bin so glücklich, ach, bin ich glücklich.» Da führt Eva die Sonja in das Nebenzimmer, legt sie auf die Chaiselongue: «Du bist doch schwul, Mensch.» «Nee, ich bin nicht schwul, ich hab noch nie eine angefasst.» «Aber mir mochste doch anfassen.» «Ja, weil ich dich so lieb habe und weil du von ihm ein Kind haben willst. Und das sollste von ihm haben»" (2002: 406).

${ }^{28}$ Koval, por el contrario, considera que la novela de Döblin marca el final de la Bildungsroman alemana: "Berlín Alexanderplatz no es una novela de formación. Sin embargo, conserva un parentesco temático con ella. Puede ser entendida como una radicalización escéptica del motivo de la difícil, trabajosa integración social del héroe -que es un factor central e ineludible en el subgénero" (KovAL 2018: 288). Sin embargo, en su estudio sobre la Bildungsroman sí indica como una característica del Bildung el hecho de que la maduración de los personajes implica una desexualización (2018: 280).
}

Pandaemonium, São Paulo, v. 24, n. 44, set.-dez. 2021, p. 374-399 
RUBINO, A.R. - Homosociabilidad y disidencia en Berlin Alexanderplatz

protagonista al final de la novela (TATAR 1992: 141). La lectura del final posiciona al protagonista como "triumphantly autonomous male subjetc" (TATAR 1992: 137). En ese sentido, al análisis feminista de Tatar se podría agregar que lo que prima al final no es sólo la desexualización sino también la definitiva negación de la posibilidad del deseo homosexual. Las lecturas sobre Berlín Alexanderplatz que menciona Tatar evitan el desorden argumentativo de la novela dándole coherencia. Pero, según ella, las interpretaciones en clave de sexo-género no fueron evidentes hasta después de la versión de Fassbinder (TATAR 1992: 135). De acuerdo a esta perspectiva, nuestra lectura de Döblin está, necesariamente, mediada por la versión de Fassbinder, que acentuó los elementos homoeróticos ya presentes en Döblin (ELISSEEVA 2017: 71). En primer lugar, porque la novela de Döblin plantea una variedad de voces y una estructura intertextual muy compleja, además de técnicas e influencias que vienen del cine y que pueden ser pensadas, entonces, desde la intermedialidad.

Para Koval, que la lee como el cierre de la novela de formación, son tres las instituciones que actúan sobre el héroe para normalizarlo y volverlo un "miembro socialmente 'útil' del colectivo: el ejército, la cárcel y el manicomio" (KovAL 2018: 270). Sin embargo, es interesante tener en cuenta que la lógica del montaje desdibuja, justamente, la fuerza de estas instituciones y la normalización aparece en la diversidad de voces y discursos: el periodismo, la publicidad, la pornografía, etc. tensionada con voces y discursos de la disidencia sexual. El Berlín de los años veinte, en ese sentido, es un campo de batalla, de disputa de sentidos en torno a la sexualidad, la normalidad y la marginación. Reinhold, de hecho, encuentra su lugar en la cárcel, es el contexto en el que puede llevar adelante su deseo homosexual. Y el propio Biberkopf recuerda la cárcel como un lugar agradable. Si la novela refleja "the conflict between the individual personality and the demands, expectations, or conventions of the society at large", como afirma Komar, y la técnica del montaje "echoes the basic dichotomy of individual versus society" (1981: 328), entonces es importante tener en cuenta que la cultura sexo-disidente del Berlín de la República de Weimar es también una parte importante. Y contrasta con la masculinidad heterosexual no tanto como algo dado naturalmente sino como una producción biopolítica que aquí pensamos con el concepto de la homosociabilidad y la melancolía de género.

A modo de conclusión, me interesa retomar ahora las palabras de Fassbinder con las que inicié el artículo. Fassbinder lee la novela de Döblin como la historia de "dos 
RUBINO, A.R. - Homosociabilidad y disidencia en Berlin Alexanderplatz

personas que se arruinan porque no se dan cuenta de que tienen una relación entre sí que, de haber estado en condiciones de admitírsela, podría haberlos hecho felices" (FASSBINDER 2018: 415). Esa imposibilidad de admitir una relación sexo-afectiva, los deseos y el placer sexo-disidente adquieren sentido cuando se recorren las alusiones a -y representaciones de- la cultura sexo-disidente del Berlín de los años veinte. Vuelvo a la escena del libro segundo en la que Franz lee las revistas con cierto rechazo pero también con fascinación. Esa reacción contradictoria es clave para pensar hasta qué punto la educación sentimental del héroe le impide ver como posibilidad lo que otras personas experimentan y defienden como una vida vivible.

\section{Referencias bibliográficas}

BUTLER, Judith. Mecanismos psíquicos del poder. Teorías sobre la sujeción. Madrid: Cátedra, 2001.

BUTLER, Judith. Cuerpos que importan. Sobre los limites materiales y discursivos del "sexo". Buenos Aires: Paidós, 2002.

BUTLER, Judith. El género en disputa. El feminismo y la subversión de la identidad. Barcelona: Paidós, 2007.

COATES, Paul. Swearing and Forswearing Fidelity in Fassbinder's Berlin Alexanderplatz. In: PEUCKER, Brigitte (ed.). A companion to Rainer Werner Fassbinder. Malden: WileyBlackwell, 2012, 398-419.

CÓRDOBA GARCÍA, David. Teoría queer: reflexiones sobre sexo, sexualidad e identidad. Hacia una politización de la sexualidad. In: CóRDOBA GARCÍA, David; SÁEZ, Javier; VIDARTE, Francisco (ed.). Teoría queer: politicas bolleras, maricas, trans, mestizas. Barcelona: Egales, 2005, 21-66.

CoRnelsen, Elcio Loureiro. Franz Biberkopf está de volta. Pandaemonium Germanicum, São Paulo, v. 14, n. 2, 250-256, 2009.

CoRnelsen, Elcio Loureiro. O estilo em Alfred Döblin. Pandaemonium Germanicum, São Paulo, v. 15, n. $1,50-69,2010$.

Crouthamel, Jason. An intimate history of the front: masculinity, sexuality, and German soldiers in the First World War. New York: Palgrave Macmillan, 2014.

DöBlIN, Alfred. Berlin Alexanderplatz. Tradução: Miguel Sáenz. Barcelona: Ediciones B, 1987.

DöBLIN, Alfred. Berlin Alexanderplatz: die Geschichte vom Franz Biderkopf. Frankfurt a. M.: Suhrkamp, 2002.

DollenMaYer, David. The Berlin Novels of Alfred Döblin. Berkeley: University of California Press, 1988.

ELISSEEVA, Aleksandra. Fassbinders „Berlin Alexanderplatz“ - Literaturverfilmung als Queer Reading. World Literature Studies, Eslováquia, v. 9, n. 4, 62-73, 2017.

ElSAESSER, Thomas. Fassbinder's Germany: history, identity, subject. Amsterdam: Amsterdam University Press, 1996.

FASSBINDER, Rainer Werner. La anarquía de la imaginación: entrevistas, ensayos y notas. Barcelona: Paidós, 2002.

FASSBINDER, Rainer Werner. Fassbinder por Fassbinder. Las entrevistas completas. Buenos

Pandaemonium, São Paulo, v. 24, n. 44, set.-dez. 2021, p. 374-399 
RUBINO, A.R. - Homosociabilidad y disidencia en Berlin Alexanderplatz

Aires: El cuenco de plata, 2018.

HILMAN, Roger. Döblin's 'Symphony of the Big City': Berlin Alexanderplatz and the Historical Novel. In: RoBerTs, David; ThOMSON, Philip (ed.). The Modern German Historical Novel: Paradigms, Problems and Perspectives. New York: Berg, 1991, 97-108.

KarlaVARIS-Bremer, Ute. Döblin und die Berlinerin. Frauengestalten in Alfred Döblins Berliner Romanen. Stauffacher, Werner (ed.). Internationale Alfred-Döblin-Kolloquien 1984-1985. Bern: Peter Lang, 1985, 176-84.

Keller, Otto. Döblins Montageroman als Epos der Moderne: Die Struktur der Romane Der schwarze Vorhang, Die drei Sprünge des Wang-lun und Berlin Alexanderplatz. München: Wilhelm Fink Verlag, 1980.

KomAR, Kathleen. Technique and Structure in Döblin's Berlin Alexanderplatz. The German Quarterly, New Jersey, v. 54, n. 3, 318-334, 1981.

Koval, Martín. Los últimos pasos de la novela de formación alemana: Berlin Alexanderplatz. Integración social y pérdida de la identidad. Revista Luthor, v. II, n. 8, n.p., 2012.

KovAL, Martín Ignacio. Vocación y renuncia. La novela de formación alemana entre la Ilustración y la Primera Guerra Mundial. Buenos Aires: EFFL, 2018.

Kuhlman, Erika. Reconstructing Patriarchy after the Great War: Women, Gender and Postwar Reconciliation between Nations. New York: Palgrave Macmillan, 2008.

OGASAWARA, Yoshihito. Literatur zeugt Literatur": Intertextuelle, motiv- und kulturgeschichtliche Studien zu Alfred Döblins Poetik und dem Roman Berlin Alexanderplatz. Frankfurt am Main: Lang, 1996.

Prangel, Matthias. Materialen zu Alfred Doeblin „Berlin Alexanderplatz“. Frankfurt am Main: Suhrkamp, 1975.

PRECIADO, Paul B. Terror anal: apuntes sobre los primeros días de la revolución sexual. In: Hocquenghem, Guy; Preciado, Paul B. El deseo homosexual (con Terror anal). Barcelona: Melusina, 2009, 133-174.

Preciado, Paul B. Manifiesto contra-sexual. Madrid: Opera Prima, 2002.

RENTSCHLER, Eric. Terms of Dismemberment: The Body in/and/of Fassbinder's Berlin Alexanderplatz (1980). New German Critique, New York, n. 34 (Winter 1985), 194-208, 1985.

RiBeIRo DE SousA, Celeste. Berlin Alexanderplatz, romance de vanguarda. Pandaemonium Germanicum, São Paulo, v. 1, n. 1, 33-43, 1997.

RuBIN, Gayle. El tráfico de mujeres: notas sobre la 'economía política' del sexo. Nueva Antropología, Coyoacán, v. 8, n. 30, 95-145, 1986.

RUBINO, Atilio. Franz Biberkopf entre la literatura y el cine: un análisis intermedial de Berlin Alexanderplatz de Alfred Döblin y el cine de Rainer Werner Fassbinder. Revista Laboratorio. Literatura y experimentación, Santiago, n. 22, n.p., 2020.

RUBINO, Atilio Raúl. Instrucciones para sacar del armario a (o salir del armario con) los clásicos de la literatura. Fassbinder y la adaptación cinematográfica de Berlin Alexanderplatz de Alfred Döblin. In: García, Jesús Rodrigo (coord.). Rainer Werner Fassbinder. Sólo quiero que me amen. Santander (España): Shangrila, 2018, 250-273.

SANDER, Gabriele. Erläuterungen und Dokumente: Alfred Döblin. "Berlin Alexanderplatz.". Stuttgart: Reclam, 1998.

SANDER, Gabriele. Döblin's Berlin: The Story of Franz Biberkopf. In: Dollinger, Roland; KöPKe, Wulf; THOMANn TEWARSOn, Heidi (ed.). A companion to the works of Alfred Döblin. Rochester: Camden House, 2004, 141-160.

SEDGWICK, Eve Kosofsky. Epistemología del armario. Barcelona: Ediciones de la Tempestad, 1998.

SHEA, Nicole. The politics of prostitution in Berlin Alexanderplatz. Oxford: Lang, 2007.

Pandaemonium, São Paulo, v. 24, n. 44, set.-dez. 2021, p. 374-399 
RUBINO, A.R. - Homosociabilidad y disidencia en Berlin Alexanderplatz

StENZEL, Jürgen. Mit Kleister und Schere. Zur Handschrift von Berlin Alexanderplatz. Text + Kritik, München, v. 13/14, 39-44, 1972.

StERnweILER, Andreas. Self-confidence and Persistence. Two Hundred Years of History, Berlín: Schwules Museum, 2004.

TATAR, Maria. 'Wie süß ist es sich zu opfern' Gender Violence and Agency in Döblin's Berlin Alexanderplatz. Deutsche Vierteljahrsschrift für Literaturwissenschaft und Geistesgeschichte, Stuttgart, v. 66, issue 3, 491-518, 1992.

WeINBACHER, Hannah Kristina. Sexualmedizinisches im Werk des Arztes und Schriftstellers Alfred Döblin (1878-1957). Dissertation zum Erwerb des Doktorgrades der Medizin an der Medizinischen Fakultät der Ludwig-Maximilians-Universität zu München, 2011.

Recebido em 4 de setembro de 2020 Aceito em 10 de outubro de 2020 